\title{
Cerebellar Haemangioblastoma Diagnosed as Giant Tuberculoma: Falacies of Magnetic Resonance Spectroscopy-Case Report
}

\author{
B. B. Sharma1*, Naveen Bhardwaj', Sakshi Dewan², Mir Rizwan Aziz', \\ Shashi Sharmaㄹ, Shilpa Singh ${ }^{3}$ \\ ${ }^{1}$ Department of Radio-Diagnosis, SGT Medical College Budhera, Gurgaon, India \\ ${ }^{2}$ Department of Pediatrics, SGT Medical College, Gurgaon, India \\ ${ }^{3}$ Faculty of Allied Health Sciences, SGT University Gurgaon, Haryana, India \\ Email: `bbhushan986@gmail.com, Drnaveenucms@gmail.com, sakshii.21@gmail.com, rizwan.gmc@gmail.com, \\ shashi.s986@gmail.com, Shilpacool@gmail.com
}

How to cite this paper: Sharma, B.B., Bhardwaj, N., Dewan, S., Aziz, M.R., Sharma, S. and Singh, S. (2017) Cerebellar Haemangioblastoma Diagnosed as Giant Tuberculoma: Falacies of Magnetic Resonance Spectroscopy-Case Report. Open Journal of Radiology, 7, 54-58.

https://doi.org/10.4236/ojrad.2017.71006

Received: February 10, 2017

Accepted: March 28, 2017

Published: March 31, 2017

Copyright $\odot 2017$ by authors and Scientific Research Publishing Inc. This work is licensed under the Creative Commons Attribution International License (CC BY 4.0).

http://creativecommons.org/licenses/by/4.0/

\section{(c) (i) Open Access}

\begin{abstract}
Background: Posterior fossa haemangioblastoma tumors are slightly rare and these originate from the brain blood vascular network. Cerebellum and brain stem are the commonest places of occurrence. These are benign and produce symptoms quite late because of their slow growing asymptomatic nature. Case report: We present 24-years old female who was wrongly diagnosed as having giant tuberculomas of the posterior fossa by MR spectroscopy. Contrast enhanced computerized tomography (CECT) and magnetic resonance imaging (MRI) studies had shown the results more in favor of tuberculoma. She was given anti-tubercular therapy (ATT) but without any much improvement. The condition aggravated by causing obstructive hydrocephalus at the level of fourth ventricle. The patient was operated upon for the mass lesion and on histopathology; it was proved to be a case of cerebellar haemangioblastoma. Conclusion: MR spectroscopy can sometimes be misleading and can lead to mis-mangemant. The reliability of spectroscopy is debatable and has to be decided on the merits along with clinical symptomatology.
\end{abstract}

\section{Keywords}

Haemangioblastoma, MR Spectroscopy, CECT, MRI, ATT, Hydrocephalus

\section{Introduction}

Haemangioblastomas constitutes $8 \%-12 \%$ masses of the posterior fossa masses as compared to $1 \%-2.5 \%$ of all the brain tumors. These are benign tumors but 
derive their blood supply from the pial vessels. These often produce symptoms by compressing the neighboring structures [1]. Haemangioblastomas are twice common in men than women and majority of these falls in 20 - 40 years age group. These have been labeled as WHO grade I benign tumors originating from the blood vessels. Sometimes the inferences of the imaging modalities can confuse the diagnosis which leads to the mismanagement as was in our case.

\section{Case Report}

24-years female reported to the outpatient department with complaints of headache of one year duration. She had occasional difficulty of balancing herself while walking. There was history of off and on low grade fever with slight evening rise in nature. She was diagnosed as posterior fossa giant tuberculomas on the basis of imaging studies and biomedical investigations. Pre-operative non contrast computerized tomography (NCCT) of head had shown posterior fossa mass which was compressing upon fourth ventricle leading to hydrocephalus (Figure 1(a) and Figure 1(b)).

Post contrast study had shown enhancement of the solid part with cystic component as hypo dense region (Figure 2).

MRI studies have shown a mixed intensity structure with avid enhancement of the mural nodule. Spectroscopy of the tumor had shown lipid and lactate peaks without any significant choline rise. NAA peak was decreased with increased Choline/Creatinine ratio. Though the possibility of haemangioblastoma was kept, but as per the laboratory investigations, spectroscopy and presentation she was labeled as a case of giant tuberculomas (Figures 3(a)-(c), Figure 4(a) and Figure 4(b) and Figures 5(a)-(c)).

She was put on ATT for six months after these findings. However the condition deteriorated and the patient had to undergo surgical excision of the mass. Histopathological findings confirmed the diagnosis of Hemangioblastoma. The

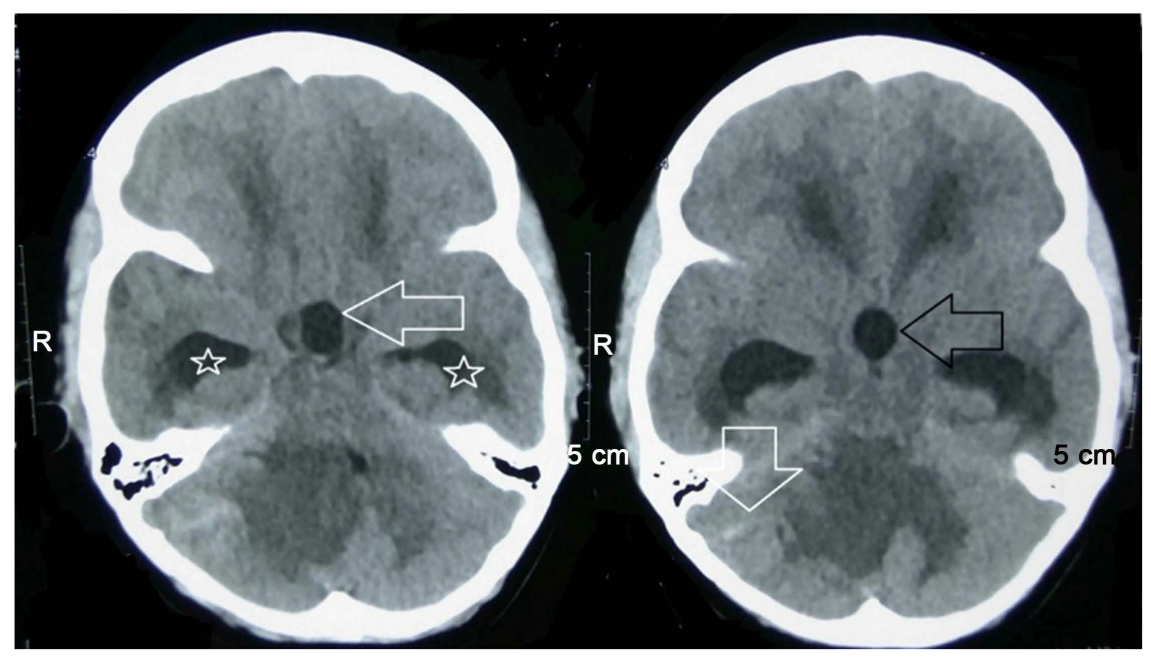

Figure 1. NCCT head axial sections: (a) at third ventricle level (white arrow) which shows moderate hydrocephalus (white stars); (b) at slightly lower level with mass lesion in the posterior fossa having mixed solid and cystic components (white inverted arrow). 


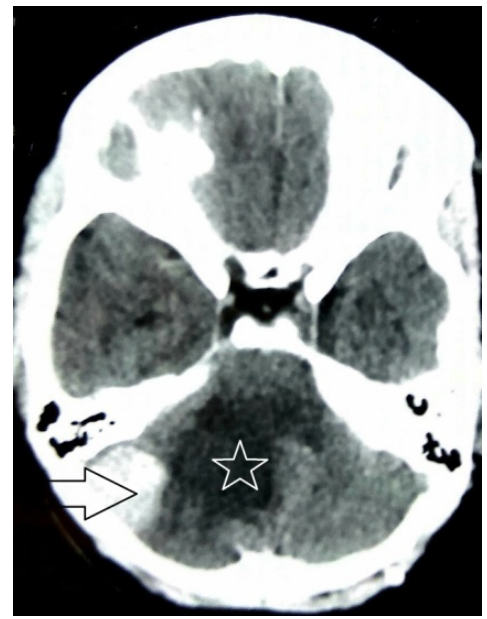

Figure 2. CECT brain axial section: There is enhancement of the solid part of the tumor (horizontal arrow) in the posterior fossa with surrounding hypo dense area (white star).

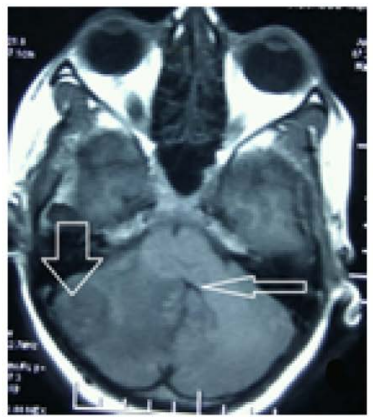

(a)

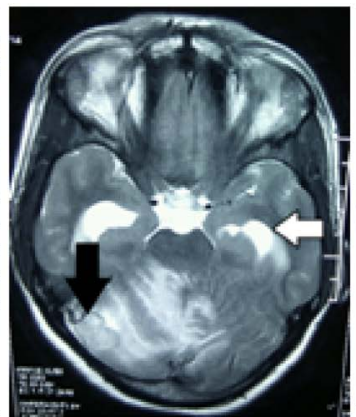

(b)

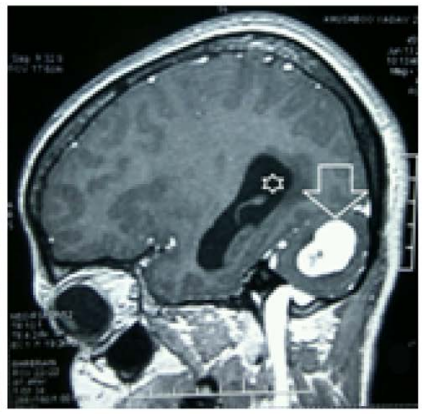

(c)

Figure 3. MR study of the same patient: (a) T1W axial section shows mixed intensity lesion (inverted white arrow) with compression of fourth ventricle (thin horizontal white arrow); (b) T2W axial section shows hyperintensity in the posterior fossa depicting peritumoral oedema predominantly on right side with hypointense peripheral solid lesion (inverted black arrow). Frontal horns on both sides shows dilatation (white arrow); (c) T1W post contrast sagittal section shows intense enhancement of the solid component (inverted white arrow) with dilatation of ventricular system (white star).

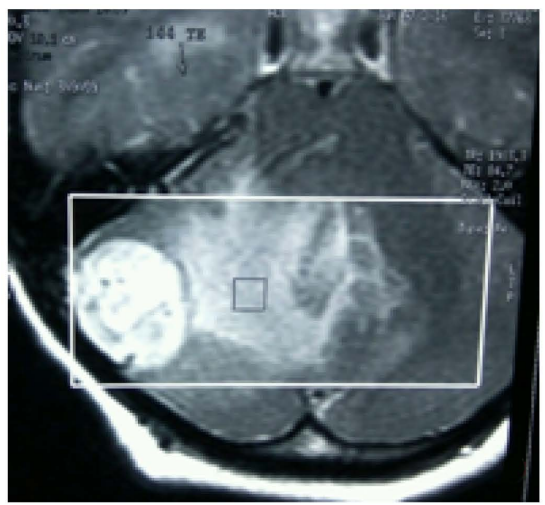

(a)

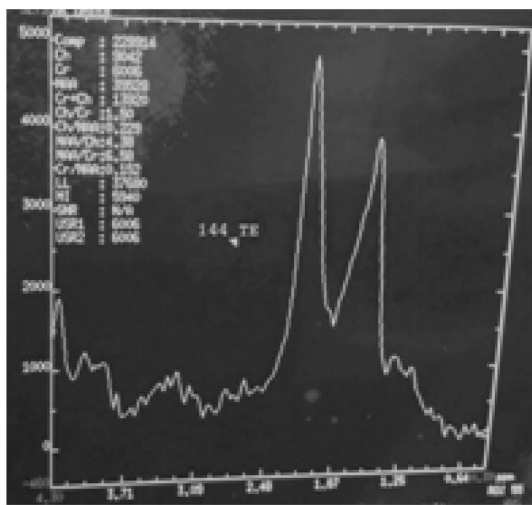

(b)

Figure 4. MR Spectroscopy: (a) T1W post contrast axial section with single voxel study; (b) MR spectroscopy shows increased lipid and lactate peaks. $\mathrm{N}$-acetyla sparate peak is decreased with increased $\mathrm{Ch} / \mathrm{Cr}$ peak. 


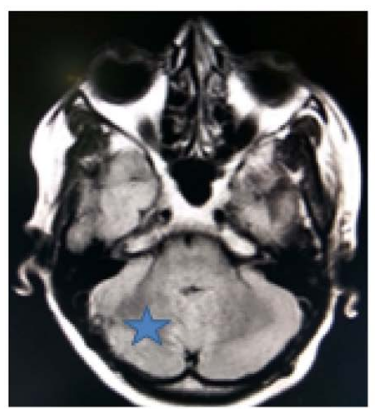

(a)

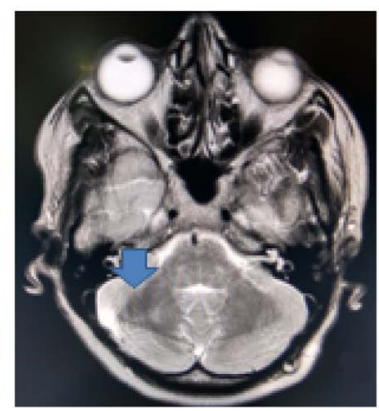

(b)

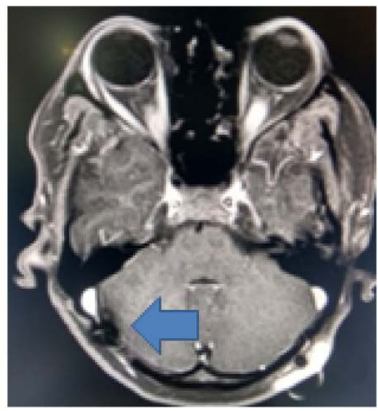

(c)

Figure 5. Brain MRI axial sections: (a) T1W image did not reveal any residual or recurrence tumor evidence (blue star); (b) T2W image almost disappearance of the findings compressing upon the forth ventricle (inverted blue arrow); (c) Post gadolinium sequences did not show any abnormal enhancement (horizontal blue arrow).

specimen was predominantly constituted abundant vacuolated stromal cells with capillary network (slides not available). Post operation CT scan was done after one month had shown encouraging result without any residual tumor.

Post surgical recovery was uneventful and the patient had been kept on six monthly follow up.

\section{Discussion}

Haemangioblastomas are slow growing tumors with tendency to rupture. These remain undiagnosed for a long time because of their asymptomatic nature. This has got a close association to the tune of $25 \%$ with von Hipple Lindau disease and rest $75 \%$ are of sporadic in nature [2]. Common complaints are headache in $70 \%$ of the cases and 50\% report with hydrocephalus. These tumors cause disturbances in movements, equilibrium and muscle tone because of cerebellar involvement. The coordination of movements is always affected. There can be sudden bleeding inside the cranial cavity because of the rupture which is a medical emergency. These can cause hydrocephalus because of compression over the CSF pathway.

Magnetic resonance imaging and computerized tomography imaging are the modalities of choice for their evaluation. On CEMRI and CECT of the brain these are well demarcated cystic masse with mural nodule and non enhancing wall [3]. Mural nodule within this cystic mass enhances vividly [4]. MR spectroscopy of haemangioblastoma shows high lipid peak without any lactate peak. Coline peak is raised with low creatinine/phosphocreatinine ratio. $\mathrm{N}$-acetylaspartate (NAA) is absent which indicates of non neurogenic origin of these tumors.MR spectroscopy in our present case had shown increased lipid peak, decreased NAA peak and increased Choline/Creatinine ratio and this was the reason for labeling her as a case of giant tuberculomas [5] [6] [7].

Management is always by surgical intervention and Gamma knife radio surgery has become the fashion of the day. The tumors can partially be drained before surgery as these constitute mixed pattern of solid and cystic. Pre surgical embolisation is done to minimize the blood loss and neat surgical excision [8]. 
Recurrence is seen in $25 \%$ of the cases associated with von Hipple-Lindau syndromes.

\section{Conclusion}

Hemangioblastomas can be best diagnosed by the modalities like CECT and MR contrast studies. But sometimes spectroscopy can mislead the issue of final diagnosis as happened in this case.

\section{Acknowledgements}

We are thankful to Mr Rajdeep, Miss Nitika and Raoushan Singh of Faculty of Allied Health Sciences SGT University Gurgaon for carrying out the study and procuring the best quality images.

\section{Consent of the Patient}

Written consent of the patient was taken for publishing this case.

\section{References}

[1] Archer, C.R., Roberson, G.H. and Taveras, J.M. (1972) Posterior Medullar Hemangioblastoma. Radiology May, 103, 323-328. https://doi.org/10.1148/103.2.323.

[2] Kurosaki, Y., Tanka, Y.O. and Itai, Y. (1997) Solid Cerebellar Hemangioblastoma with an Evolving Large Cystic Component. European Radiology, 7, 910-912. https://doi.org/10.1007/s003300050226.

[3] Ister, A.D. and Arthur, D.W. (1988) Intracranial Hemangioblastomas: CT and MRI Findings. Journal of Computer Assisted Tomography, 12, 736-739. https://doi.org/10.1097/00004728-198809010-00003.

[4] Lee, S.R., Sanches, J., Mark, A.S., Dillon, W.P. and Norman, T.H. (1989) Posterior Fossa Hemangioblastomas: MR Imaging. Radiology, 171, 463-468. https://doi.org/10.1148/radiology.171.2.2704812.

[5] Ho, V.B., Smirniotopoulos, J.G., Murphy, F.M. and Rushing, E.J. (1992) Radiologic-Pathologic Correlation: Hemangioblstoma. American Journal of Neuroradiology, 13, 1343-1352.

[6] Santy, K., Nan, P., Chantana, Y., et al. (2011) The Diagnosis of Brain Tuberculomas by H-Magnetic Resonance Spesctroscopy. European Journal of Pediatrics, 170, 379-387. https://doi.org/10.1007/s00431-011-1408-7.

[7] Isobe, T., Yamamoto, T., Akutsu, H., Anno, I., Shiigai, M., Zaboronok, A., Masumoto, T., Takano, S. and Matsumura, A. (2010) Proton Magnetic Resonance Spectroscopy Findings of Hemangioblastoma. Japanese Journal of Radiology, 28, 318-321. https://doi.org/10.1007/s11604-010-0421-5

[8] Symon, L., Murota, T., Pell, M. and Bordi, L. (1993) Surgical Management of Hemangioblastoma of the Posterior Fossa. Acta Neurochirurgica, 120, 103-110. https://doi.org/10.1007/BF02112026. 
Submit or recommend next manuscript to SCIRP and we will provide best service for you:

Accepting pre-submission inquiries through Email, Facebook, LinkedIn, Twitter, etc. A wide selection of journals (inclusive of 9 subjects, more than 200 journals)

Providing 24-hour high-quality service

User-friendly online submission system

Fair and swift peer-review system

Efficient typesetting and proofreading procedure

Display of the result of downloads and visits, as well as the number of cited articles Maximum dissemination of your research work

Submit your manuscript at: http://papersubmission.scirp.org/

Or contact ojrad@scirp.org 